\title{
Risk factors of grade $\geq 2$ radiation pneumonitis after gemcitabine induction chemotherapy for patients with non-small cell lung cancer
}

\author{
Liming Sheng ${ }^{1,2+}$, Xiaoying Cui ${ }^{3 \dagger}$, Lei Cheng ${ }^{1,2}$, Ying Chen ${ }^{1,2}$ and Xianghui Du ${ }^{1,2^{*}}$
}

\begin{abstract}
Objectives: To observe the risk factors affecting the occurrence of RP after gemcitabine-based induction chemotherapy.

Methods: Between January 2010 and December 2017, patients with NSCLC received gemcitabine or docetaxel chemotherapy, followed by radiotherapy at Zhejiang cancer hospital were enrolled in this study. Patients were treated with gemcitabine or docetaxel induction chemotherapy, followed by radiotherapy or concurrent chemoradiotherapy. Acute radiation pneumonitis was scored post chemoradiotherapy.

Results: One hundred and eighty-four patients with NSCLC were included in the gemcitabine group and 144 in the docetaxel group. The gemcitabine group experienced a higher incidence of grade $\geq 2 \mathrm{RP}$, compared with docetaxel group (25.5\% Vs. 13.2\%, $P=0.005)$. The optimal cutoff values of lung $V_{5}, V_{20}, V_{30}$ and MLD were set at $44 \%$ (AUC [area under the curve] $=0.593), 24 \%(A \cup C=0.607), 14.2 \%(A \cup C=0.622)$ and $1226 \mathrm{cGy}(\mathrm{AUC}=0.626)$. On multivariate analysis, only lung $V_{30}$ was identified as a predictor for grade $\geq 2 \mathrm{RP}(P=0.03)$. The grade $\geq 2 \mathrm{RP}$ rate was only $9.4 \%$ for the low-risk group (Lung $V_{5} \leq 44 \%, V_{20} \leq 24 \%, V_{30} \leq 14.2 \%$, and MLD $\leq 1226$ cGy) in patients received gemcitabine induction chemotherapy.

Conclusions: Gemcitabine chemotherapy before thoracic radiotherapy in NSCLC patients was related to a higher incidence of grade $\geq 2 \mathrm{RP}$, compared with docetaxel chemotherapy. The Lung dose-volume variable $V_{30}$ was the best predictor of grade $\geq 2 \mathrm{RP}$.
\end{abstract}

Keywords: Non-small cell lung cancer, Radiation pneumonitis, Risk factor, Dose-volume variable

\section{Introduction}

Concurrent chemoradiotherapy is the standard treatment for locally advanced non-small cell lung cancer (NSCLC) [1]. Historically, the treatment of NSCLC has evolved from radiotherapy alone to combined chemoradiotherapy. It took 40 years for the standard treatment model of concurrent chemoradiotherapy to be established. RTOG9410 clinical trial showed that compared

\footnotetext{
* Correspondence: shenglm@zjcc.org.cn

Liming Sheng and Xiaoying Cui are first joint authors.

1 Department of radiotherapy, Cancer Hospital of University of Chinese

Academy of Sciences, Zhejiang Cancer Hospital, Hangzhou, China

${ }^{2}$ Institute of Cancer Research and Basic Medical Science of Chinese Academy

of Sciences, 1 Banshandong Road, Hangzhou 310022, Zhejiang, China

Full list of author information is available at the end of the article
}

with sequential chemoradiotherapy, concurrent chemoradiotherapy could significantly prolong the median survival time of NSCLC patients, without the increasing treatment-related toxicities [2]. In 2010, a meta-analysis based on six randomized controlled clinical trials showed that compared with sequential chemoradiotherapy, concurrent chemoradiotherapy reduced the risk of death by $16 \%$ and increased the 3-year survival rate by $5.7 \%$ in patients with locally advanced NSCLC that could not be resected [3]. Although the toxicities of concurrent chemoradiotherapy may be higher and more severe, it does not increase treatment-related deaths compared with sequential chemoradiotherapy. Based on these findings, concurrent chemoradiotherapy is strongly 
recommended for locally advanced non-resectable NSCLC patients in the current guidelines.

Current guidelines do not routinely recommend induction chemotherapy for patients with non-small cell lung cancer who can receive concurrent chemoradiotherapy, according to the result of CALGB 39801 [4]. However, in patients with large pulmonary tumors or bulky nodal metastasis, induction chemotherapy could reduce the size of the masses so that the radiotherapy plan can be safely performed [5]. Gemcitabine, a cytosine nucleoside derivative, is one of the commonly used drugs in induction chemotherapy of NSCLC [6, 7]. However, it is not recommended for concurrent use with radiotherapy due to its obvious pulmonary toxicity $[8,9]$. Even with sequential gemcitabine and radiotherapy, the incidence of radiation pneumonitis (RP) is still high [10]. The understanding of RP has been developed due to the advances in clinical and molecular biology research, but this complication could not be thoroughly avoided. RP seriously affects the quality of life and long-term survival of lung cancer patients [11].

Numerous clinical and dosimetric parameters are associated with RP [12-14]. Dosimetric parameters, including mean lung dose (MLD), $V_{5}, V_{20}, V_{30}$, are still the best predictors of RP at present [15]. To reduce the risk of RP, the National Comprehensive Cancer Network $(\mathrm{NCCN})$ guidelines limit the dose-volume parameters of lungs as follows: $\mathrm{MLD} \leq 20 \mathrm{~Gy}, \mathrm{~V}_{20} \leq 35 \%$ and $\mathrm{V}_{5} \leq 65 \%$. However, these constraints are based on clinical observations of concurrent chemoradiotherapy for NSCLC. For patients receiving induction chemotherapy, these parameter constraints may be too strict. However on the other hand, for patients who received gemcitabine-based induction chemotherapy and then received thoracic radiotherapy, the restriction might be too loose.

Therefore we conducted this retrospective study to observe whether different chemotherapeutic regimens in induction chemotherapy before radiotherapy affected the incidence of RP. Furthermore, another aim of this study was to observe the factors affecting the occurrence of RP after gemcitabine-based induction chemotherapy. We further used dosimetric factors to generate a predictive model to identify the risk of RP in patients who received gemcitabine chemotherapy before thoracic radiotherapy.

\section{Methods}

\section{Patients}

Between January 2010 and December 2017, 461 patients with NSCLC received gemcitabine or docetaxel chemotherapy followed by radiotherapy at Zhejiang cancer hospital. The inclusion criteria were as followed: Newly histologically or cytologically confirmed NSCLC; clinical stage IIIA or IIIB; inoperable; four cycles of gemcitabine plus cisplatin or docetaxel plus cisplatin chemotherapy before radiotherapy; completion of chest radiotherapy.
The exclusion criteria included receiving surgery before or after chemoradiotherapy $(n=85)$ or a total radiotherapy dose of less than $40 \mathrm{~Gy}(n=48)$. Finally, 328 patients were enrolled in this study. This study was approved by the Zhejiang cancer hospital institutional review board. Patients' age, gender, tumor location, histology, TNM stage, chemotherapy regimens, chemotherapy cycles, the interval between chemotherapy and radiotherapy, total radiotherapy dose, and dose per fraction were collected from the medical record.

\section{Chemotherapy}

Gemcitabine or docetaxel was selected as a chemotherapy regimen according to pathological type, economic situation, and personal willingness. Patients were treated with gemcitabine at a dose of $1000 \mathrm{mg} / \mathrm{m}^{2}$ in $100 \mathrm{~mL}$ of normal saline solution by $30 \mathrm{~min}$ intravenous infusion on days 1 and 8 with cisplatin. Docetaxel was administered at a dose of $75 \mathrm{mg} / \mathrm{m}^{2}$ by $1 \mathrm{~h}$ with standard premedications. Cisplatin was administered at a dose of $25 \mathrm{mg} /$ $\mathrm{m}^{2}$ once a day for 3 days. The treatment was repeated every 3 weeks for a total of four courses. The dose of chemotherapy drugs will be modified by a $20 \%$ decrease if grade 3-4 chemotherapy-induced toxicities occur. The interval between induction chemotherapy and radiotherapy was about 4 weeks. Radiotherapy could be postponed in case of severe toxicities or poor PS status.

\section{Radiotherapy}

Patients lied down of a wide aperture CT simulator couch in a supine position. A lightweight thermoplastic body mask was used to cover the lower neck, supraclavicular, chest, and upper abdomen. Each patient underwent CT scans ranging from neck, chest, and upper abdomen with intravenous contrast. After scans, the CT images were imported into the Ray-station data management system. Then the gross tumor volume (GTV), clinical tumor volume (CTV), and organs at risk (OARs) were contoured. The OARs included the left and right lungs, esophagus, heart, and spinal cord. The GTV was delineated according to CT images, PET-CT images, and bronchoscope. The CTV was contoured as GTV plus an area bounded by a margin of $5-10 \mathrm{~mm}$ depends on the tumor's pathology. The PTV (Planning target volume) was defined as the CTV plus $5-10 \mathrm{~mm}$ to account for the daily setup variation and respiratory movement. Radiotherapy was administered in $2.0 \mathrm{~Gy}$ once daily for 5 days per week up to a total dose of $60 \mathrm{~Gy}$. The dose-volume histogram (DVH) was obtained for PTV, lung, heart, and spinal cord. Weekly concurrent chemotherapy with paclitaxel $\left(60 \mathrm{mg} / \mathrm{m}^{2}\right)$ and carboplatin $(A U C=2)$ was administered in some patients if their PS status permitted. 


\section{Assessment of acute RP}

Acute radiation pneumonitis was scored monthly after chemoradiotherapy, using the National Cancer Institute's Common Terminology Criteria for Adverse Events (CTCAE), version 5.0 as follows: grade 1 , asymptomatic, clinical or diagnostic observations only, intervention not indicated; grade 2, symptomatic, medical intervention indicated, limiting instrumental activities of daily living (ADL); grade 3, severe symptoms, limiting self-care ADL, oxygen indicated; grade 4, life-threatening respiratory compromise, urgent intervention indicated (e.g., tracheostomy or intubation); and grade 5 , death. RP is a comprehensive diagnosis made by radiotherapy oncologist and imaging specialists in combination with radiotherapy history, symptoms, and CT images. The endpoint in this study was grade $\geq 2 \mathrm{RP}$.

\section{Statistical analysis}

Clinical variables including gender, age, tumor location, $\geq 2 \mathrm{RP}$, and tumor stage were tested for differences between the gemcitabine group and docetaxel group by Pearson's $X^{2}$ test. DVH metrics such as patient's total lung volume, PTV volume, lung $\mathrm{V}_{5}, \mathrm{~V}_{20}, \mathrm{~V}_{30}$, and MLD were also analyzed. The discriminative ability of lung DVH parameters (lung $\mathrm{V}_{5}, \mathrm{~V}_{20}, \mathrm{~V}_{30}$, and MLD) was determined according to the receiver operating characteristic (ROC) curves, and the corresponding AUC were calculated. The optimal cut-off point was calculated with an optimal-corrected classified value to provide the best available sensitivity and specificity, based on the Youden index (sensitivity + specificity -1 ). The associations between lung DVH parameters and the risk for $\geq 2 \mathrm{RP}$ was evaluated using unconditional logistic regression analysis. RP-free survival was defined as the time from the last day of radiotherapy to the earliest onset of radiation pneumonitis or last clinical follow-up, where those alive without pneumonitis were censored at the last clinical follow-up date. Survival curves were estimated using the Kaplan-Meier method and compared using the log-rank test. We used the Cox proportional hazards model with the backward selection method for multivariate analysis. All factors with effects $\geq 2 \mathrm{RP}$ in univariate analysis $(\mathrm{P}<$ $0.05)$ were included in the multivariate analysis. All statistical calculations were performed with SPSS 13.0 for Windows (Chicago, IL, USA). A $P$-value of less than 0.05 was considered statistically significant.

\section{Results}

\section{Patients' characteristics}

A total of 328 NSCLC patients were enrolled in this study. Clinical, pathological, treatment, and RP characteristics of the patients in the two groups are shown in Table 1. All patients in this study were treated with four cycles of gemcitabine plus cisplatin or docetaxel plus cisplatin followed by thoracic radiotherapy. The study
Table 1 The relationship between patients' characteristics and chemotherapy regimens

\begin{tabular}{|c|c|c|c|c|}
\hline Variables & $\mathrm{N}$ & Gemcitabine & Docetaxel & $P$ \\
\hline \multicolumn{5}{|l|}{ Gender } \\
\hline Female & 28 & 15(53.6) & $13(46.4)$ & \multirow[t]{2}{*}{0.843} \\
\hline Male & 300 & 169(56.3) & $131(43.7)$ & \\
\hline \multicolumn{5}{|l|}{ Age } \\
\hline$<65$ & 210 & $112(53.3)$ & $98(46.7)$ & \multirow[t]{2}{*}{0.203} \\
\hline$\geq 65$ & 118 & $72(61.0)$ & $46(39.0)$ & \\
\hline \multicolumn{5}{|l|}{ Tumor location } \\
\hline Left & 145 & 85(58.6) & $60(41.4)$ & \multirow[t]{2}{*}{0.434} \\
\hline Right & 183 & $99(54.1)$ & $84(45.9)$ & \\
\hline \multicolumn{5}{|l|}{ Histology } \\
\hline SCC & 242 & 140(57.9) & $102(42.1)$ & \multirow[t]{3}{*}{0.482} \\
\hline Ade & 59 & $29(49.2)$ & $30(50.8)$ & \\
\hline Others & 27 & 15(55.6) & $12(44.4)$ & \\
\hline \multicolumn{5}{|l|}{ Concurrent CRT } \\
\hline Yes & 253 & $146(57.7)$ & 107(42.3) & \multirow[t]{2}{*}{0.281} \\
\hline No & 75 & $38(50.7)$ & $37(49.3)$ & \\
\hline \multicolumn{5}{|l|}{ T stage } \\
\hline $\mathrm{T}_{1-2}$ & 187 & 107(57.2) & $80(42.8)$ & \multirow[t]{2}{*}{0.637} \\
\hline$T_{3-4}$ & 141 & 77(54.6) & $64(45.4)$ & \\
\hline \multicolumn{5}{|l|}{ N stage } \\
\hline $\mathrm{N}_{0-1}$ & 64 & $42(65.6)$ & $22(34.4)$ & \multirow[t]{2}{*}{0.087} \\
\hline $\mathrm{N}_{2-3}$ & 264 & 142(53.8) & $122(46.2)$ & \\
\hline \multicolumn{5}{|l|}{ PTV volume } \\
\hline$\leq 330 \mathrm{cc}$ & 164 & 95(57.9) & $69(42.1)$ & \multirow[t]{2}{*}{0.504} \\
\hline$>330 \mathrm{cc}$ & 164 & $89(54.3)$ & $75(45.7)$ & \\
\hline \multicolumn{5}{|l|}{ Lung volume } \\
\hline$\leq 3248 c c$ & 177 & 101(57.1) & $76(42.9)$ & \multirow[t]{2}{*}{0.703} \\
\hline$>3248 c c$ & 151 & 83(55.0) & $68(45.0)$ & \\
\hline \multicolumn{5}{|l|}{$V_{5}$} \\
\hline$\leq 44$ & 160 & $95(59.4)$ & 65 (40.6) & \multirow[t]{2}{*}{0.243} \\
\hline$>44$ & 168 & 89 (53.0) & 79 (47.0) & \\
\hline \multicolumn{5}{|l|}{$V_{20}$} \\
\hline$\leq 24$ & 187 & $114(61.0)$ & $73(39.0)$ & \multirow[t]{2}{*}{0.041} \\
\hline$>24$ & 141 & 70 (49.6) & $71(50.4)$ & \\
\hline \multicolumn{5}{|l|}{$V_{30}$} \\
\hline$\leq 14.2$ & 122 & 71 (57.4) & $52(42.6)$ & \multirow[t]{2}{*}{0.691} \\
\hline$>14.2$ & 205 & $113(55.1)$ & $92(44.9)$ & \\
\hline \multicolumn{5}{|l|}{ MLD } \\
\hline$\leq 1226$ cGy & 164 & $106(64.6)$ & $58(35.4)$ & 0.002 \\
\hline$>1266$ cGy & 164 & 78 (47.6) & $86(52.4)$ & \\
\hline $\mathrm{RP}$ & & & & \\
\hline 1 & 262 & 137(52.3) & $125(47.7)$ & 0.006 \\
\hline 2 & 49 & $32(65.3)$ & $17(34.7)$ & \\
\hline
\end{tabular}


Table 1 The relationship between patients' characteristics and chemotherapy regimens (Continued)

\begin{tabular}{cllll}
\hline Variables & $N$ & Gemcitabine & Docetaxel & $P$ \\
\hline $3-4$ & 17 & $15(88.2)$ & $2(11.8)$ & \\
\hline
\end{tabular}

CRT Chemoradiotherapy, MLD Meal lung dose, RP Radiation Pneumonitis

patients had a median age of 62 years (range: $30-77$ years). Three hundred patients were male, and 28 were female. Two hundred and forty-two (73.8\%) were lung squamous cell carcinoma, 59 (18.0\%) were lung adenocarcinoma, and $27(8.2 \%)$ were other types. According to the new IASLC (International Association for the Study of Lung Cancer) staging system, 40 (12.2\%), 147 (44.8\%), 68 (20.7\%) and $73(22.3 \%)$ had $\mathrm{T}_{1}, \mathrm{~T}_{2}, \mathrm{~T}_{3}$ and $\mathrm{T}_{4}$ disease, respectively. One hundred and 84 were included in the gemcitabine group and 144 in the docetaxel group. Two hundred and fifty-three patients received concurrent chemoradiotherapy, while 75 patients received radiotherapy. There was no significant difference in clinicopathological variables between the two groups $(P>0.05)$. The median PTV volume was $324.8 \mathrm{cc}$ in the gemcitabine group and $343.2 \mathrm{cc}$ in the docetaxel group. No significant difference in PTV volume was found between two groups $(P=0.504)$. A similar result was found when total lung volume was compared $(P=0.703)$.

\section{RP}

Of all patients included in this study, 66 patients (20.1\%) developed grade $\geq 2$ RP, 49 (14.9\%) grade 2 and 17 (5.2\%) grade 3 or 4. In Pearson's $X^{2}$ test, the gemcitabine group experienced a higher incidence of grade $\geq 2 \mathrm{RP}$, compared with docetaxel group $(25.5 \%$ Vs. $13.2 \%, P=0.005)$, shown in Table 1 .

\section{Determination of the optimal cut-off value of DVH variables}

ROC analysis was performed, and the curves with AUCs were shown in Fig. 1 . The AUCs for lung $V_{5}, V_{20}, V_{30}$, and MLD are all statistically significant $(P<0.05)$. After

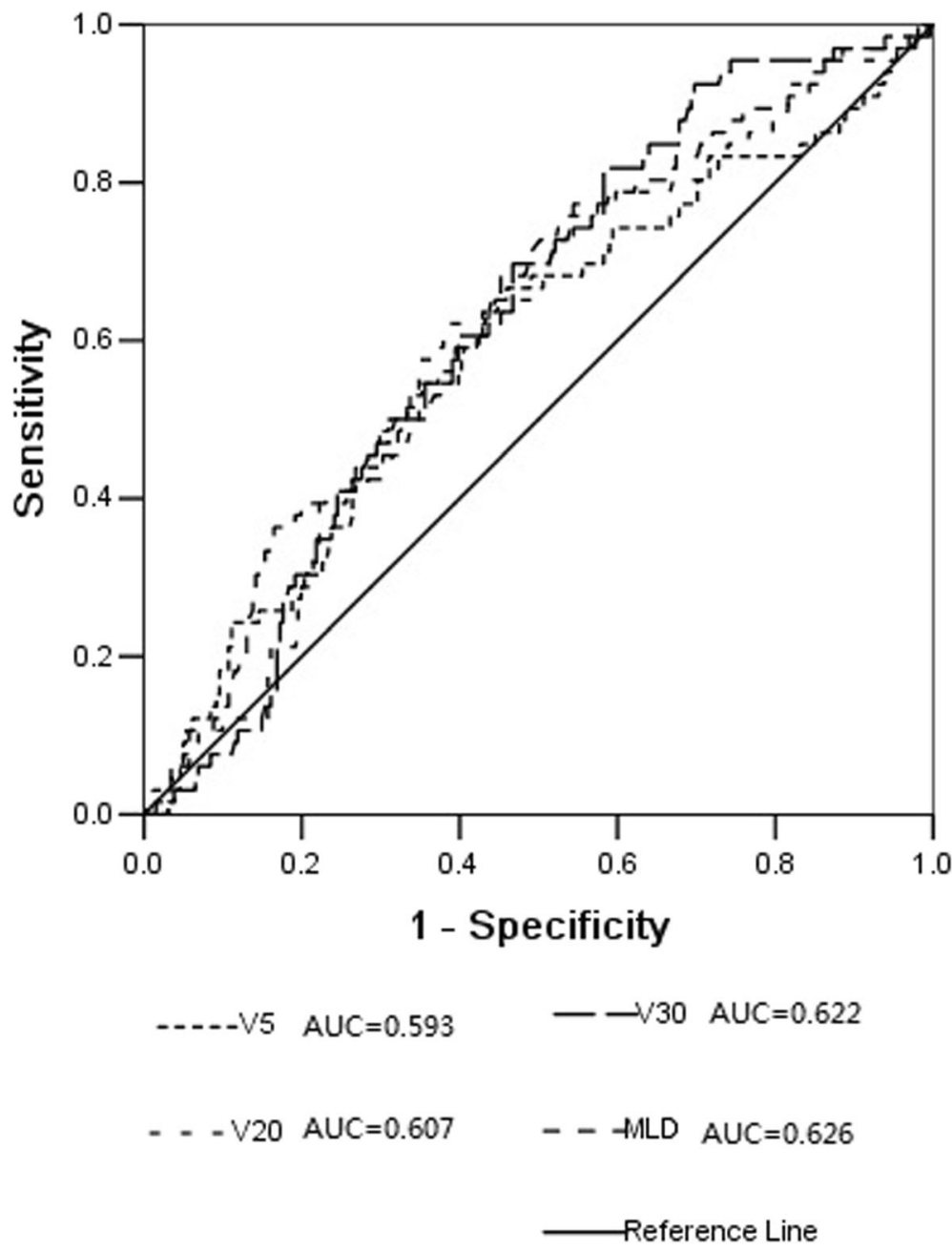

Fig. 1 Receiving operator characteristic curve based on the sensitivity and specificity of lung $V_{5}, V_{20}, V_{30}$, and MLD 
calculation the highest Youden index, the optimal cutoff values of lung $\mathrm{V}_{5}, \mathrm{~V}_{20}, \mathrm{~V}_{30}$ and MLD were set at $44 \%$ $(\mathrm{AUC}=0.593), 24 \%(\mathrm{AUC}=0.607), 14.2 \%(\mathrm{AUC}=0.622)$ and $1226 \mathrm{cGy}(\mathrm{AUC}=0.626)$. Enrolled patients were stratified into high or low level by various DVH variables based on ROC analysis.

\section{Risk factors for grade $\geq \mathbf{2}$ RP}

On univariate analysis, gemcitabine chemotherapy was associated with 2.26-fold elevated risk for grade $\geq 2$ RP (95\% CI: $1.26-4.05, \quad P=0.006)$, compared with docetaxel chemotherapy. Then we investigated the risk factors for $\mathrm{RP}$ in the gemcitabine group. Lung $\mathrm{V}_{5}, \mathrm{~V}_{20}, \mathrm{~V}_{30}$, and MLD were all associated with increased risk of grade $\geq 2 \mathrm{RP}$ in univariate analysis (Table 2). To find the independent risk factors, a multivariate logistic regression model was built. On multivariate analysis, only lung $\mathrm{V}_{30}$ was identified as a predictor for grade $\geq 2 \mathrm{RP}(P=0.03$, shown in Table 3$)$. Compared with low lung $V_{30}(\leq 14.2 \%)$, high $V_{30}(>14.2 \%)$ was associated with 2.92-fold increased risk of RP.

\section{RP-free survival}

In the whole cohort, patients treated with gemcitabine was associated with a shorter interval of RP-free survival when compared with those treated with docetaxel (Fig. 2, $P=0.026)$. In the group of gemcitabine, RP-free survival did not differ by patients gender $(P=0.612)$. Neither total lung volume, nor PTV volume was significantly differenced for RP-free survival $(P>0.05)$. Moreover, patients' age, $\mathrm{T}$ stage, and $\mathrm{N}$ stage did not seem to have an impact on RP-free survival $(P>0.05)$. All DVH parameters, such as lung $\mathrm{V}_{5}, \mathrm{~V}_{20}, \mathrm{~V}_{30}$, and MLD, were relevant to RP-free survival $(P<0.05)$.

Furthermore, we created a risk model that comprised the following factors: lung $V_{5}$ (score 0 when $\leq 44 \%, 1$
Table 3 Multivariable analysis for RP $\geq 2$ in patients treated with gemcitabine

\begin{tabular}{llll}
\hline Factors & \multicolumn{3}{l}{ Multivariable analysis } \\
\cline { 2 - 4 } & $\mathrm{HR}$ & $95 \% \mathrm{Cl}$ & $P$ \\
\hline Lung $V_{5}$ & 1.87 & $0.82-4.27$ & 0.14 \\
$>44 V_{s} \leq 44$ & 1.68 & $0.59-4.80$ & 0.33 \\
Lung $V_{20}$ & & & \\
$>24 V_{s} \leq 24$ & 2.92 & $1.10-7.74$ & 0.03 \\
Lung $V_{30}$ & & & \\
$>14.2 V_{s} \leq 14.2$ & 0.49 & $0.15-1.56$ & 0.23 \\
MLD & & & \\
$>1226$ cGy $V_{s} \leq 1226$ cGy & &
\end{tabular}

when $>44 \%$ ), lung $\mathrm{V}_{20}$ (score 0 when $\leq 24 \%$, 1 when $>24 \%$ ), lung $\mathrm{V}_{30}$ (score 0 when $\leq 14.2 \%$, 1 when $>14.2 \%$ ) and MLD (score 0 when $\leq 1226$ cGy, 1 when $>1226$ cGy). Then we grouped patients according to the sum of above scores: the high-risk group, patients with a score of 4; the intermediate-risk group, patients with a score of 1-3; the low-risk group, patients with a score of 0 . Remarkably, the low-risk group was associated with a longer interval of RP-free survival (Fig. 3, $P=0.001$ ). The grade $\geq 2$ RP rate was $9.4 \%$ for the low-risk group (5 of 53 patients), $24.7 \%$ for the intermediate group (19 of 77 patients) and $42.6 \%$ for the high-risk group (23 of 54 patients).

\section{Discussion}

In this study, gemcitabine chemotherapy before thoracic radiotherapy in NSCLC patients was related to a higher incidence of grade $\geq 2 \mathrm{RP}$, compared with docetaxel chemotherapy. The frequency of RP varies with the use of different chemotherapeutic drugs during thoracic radiotherapy [16]. The risk of RP following early chemotherapy drugs combined with radiotherapy such as bleomycin, procarbazine, and ifosfamide was 38,26 , and

Table 2 Association of RP with dose-volume variables

\begin{tabular}{|c|c|c|c|c|c|c|c|c|}
\hline \multirow[b]{2}{*}{ Variable } & \multicolumn{4}{|c|}{ Gemcitabine } & \multicolumn{4}{|c|}{ Docetaxel } \\
\hline & $n$ & Grade $\geq 2$ RP, n(\%) & Hazard Ratio & $P$ & $n$ & Grade $\geq 2$ RP, n(\%) & Hazard Ratio & $P$ \\
\hline \multicolumn{9}{|l|}{ Lung $V_{5}$} \\
\hline$\leq 44$ & 95 & 14 & 1 & 0.001 & 65 & 8 & 1 & 0.781 \\
\hline$>44$ & 89 & 33 & $3.41(1.67-6.95)$ & & 79 & 11 & $1.15(0.43-3.06)$ & \\
\hline \multicolumn{9}{|l|}{ Lung $V_{20}$} \\
\hline$\leq 24$ & 114 & 18 & 1 & $<0.001$ & 73 & 7 & 1 & 0.200 \\
\hline$>24$ & 70 & 29 & $3.77(1.89-7.54)$ & & 71 & 12 & $1.92(0.71-5.19)$ & \\
\hline \multicolumn{9}{|l|}{ Lung $V_{30}$} \\
\hline$\leq 14.2$ & 71 & 9 & 1 & 0.002 & 52 & 4 & 1 & 0.151 \\
\hline$>14.2$ & 113 & 38 & $3.49(1.57-7.77)$ & & 92 & 15 & $2.34(0.73-7.46)$ & \\
\hline \multicolumn{9}{|l|}{ MLD } \\
\hline$\leq 1226$ cGy & 106 & 17 & 1 & 0.001 & 58 & 4 & 1 & 0.076 \\
\hline$>1226$ cGy & 78 & 30 & $3.27(1.64-6.53)$ & & 86 & 15 & $2.85(0.90-9.08)$ & \\
\hline
\end{tabular}




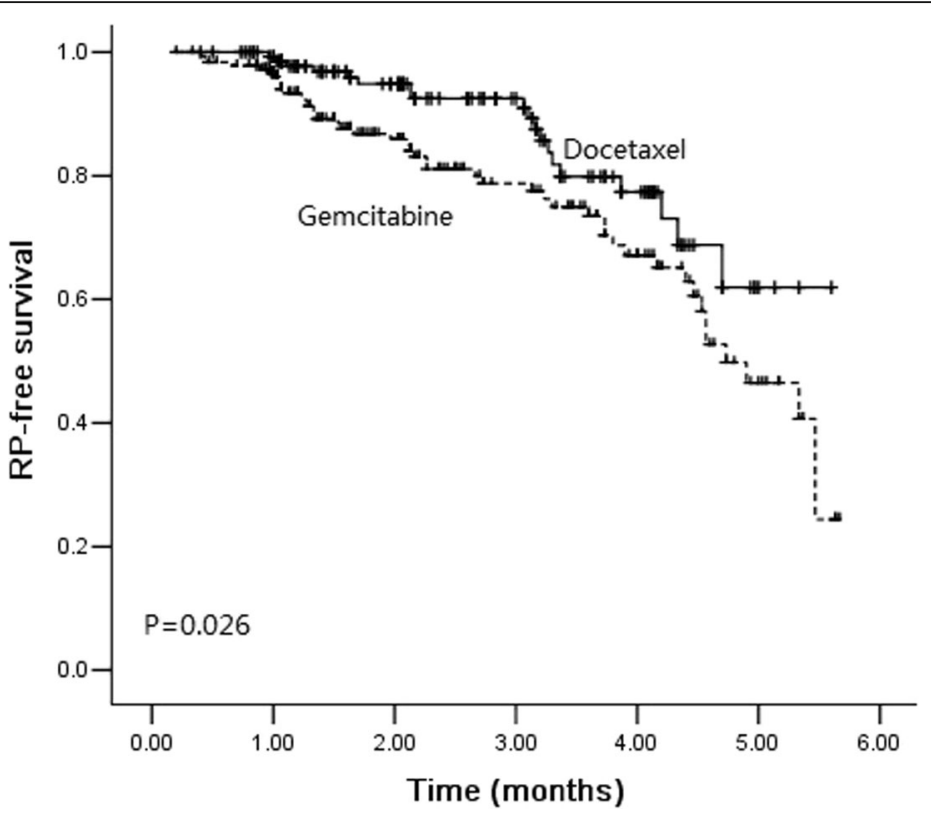

Fig. 2 Kaplan-Meier estimates of radiation pneumonitis-free survival between gemcitabine group and docetaxel group

$20 \%$, respectively. Because of the high toxicities of treatment, these drugs were gradually replaced by a new generation of drugs with low toxicities. Subsequent clinical observations also confirmed the relatively low pulmonary toxicities of cisplatin [17], carboplatin, and paclitaxel [1]. The incidence of RP after pemetrexed based concurrent chemoradiotherapy was only $1.8 \%$, according to PROCLAIM study [18]. Gemcitabine has been shown to have efficacy as a single agent or in combination with other chemotherapeutic agents for lung cancer, especially lung squamous cell carcinoma [19]. However, its pulmonary toxicity limits widespread use, especially in combination with thoracic irradiation [20]. In the present study, $25.5 \%$ of patients who received gemcitabine chemotherapy before radiotherapy developed grade $\geq 2$ RP. This result was comparable to the $22 \%$ which was found by Kosmidis $\mathrm{P}$ et al. [21].

Many studies have demonstrated that gemcitabinebased chemoradiotherapy was active, with a satisfactory

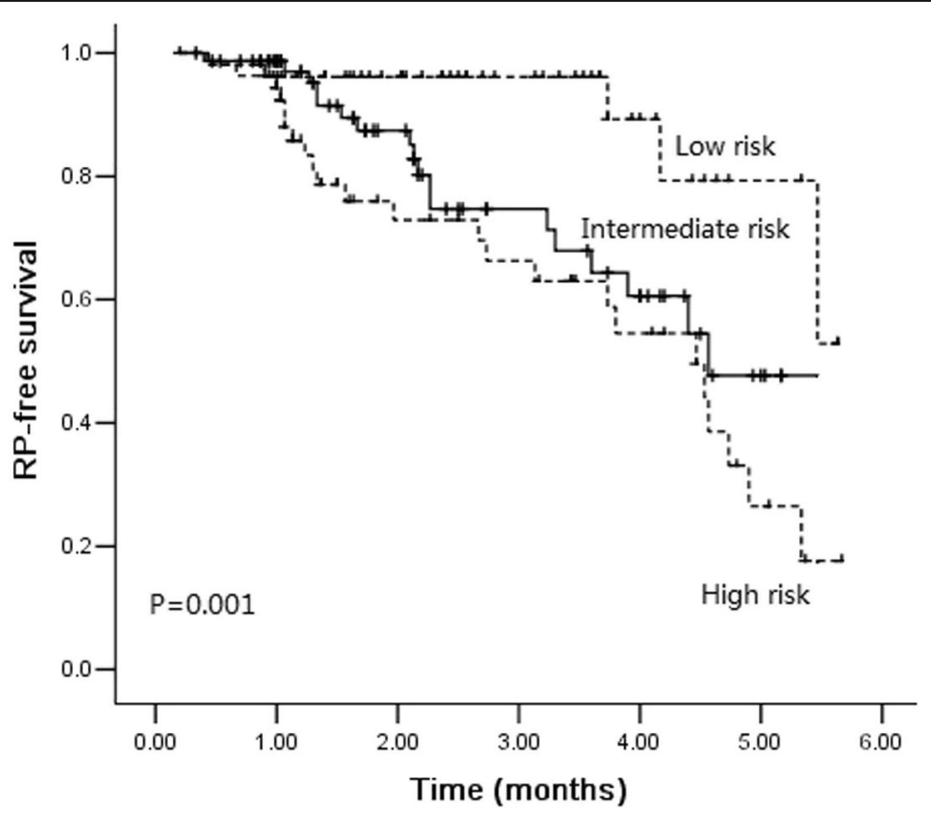

Fig. 3 Kaplan-Meier estimates of radiation pneumonitis-free survival among different risk groups 
prognosis. However, its pulmonary toxicity was intolerable. The RP occurrence in NSCLC patients who received gemcitabine-based induction chemotherapy has been studied in several publications (Shown in Table 4) [10, 21-28]. The rate of grade $\geq 3 \mathrm{RP}$ in patients who received sequential radiotherapy after gemcitabine-based induction chemotherapy was about $15 \%$ [22, 24]. When patients with locally advanced NSCLC treated with concurrent radiotherapy and low dose gemcitabine after induction chemotherapy with gemcitabine, the frequency of grade $\geq 3 \mathrm{RP}$ was $35 \%[23,25,26]$. Arrieta et al. [26] treated patients with stage IIIA or IIIB NSCLC using gemcitabine $\left(800 \mathrm{mg} / \mathrm{m}^{2}\right)$ and carboplatin (area under the curve $[\mathrm{AUC}]=2.5$ ) every 3 weeks for two cycles, followed by conventional fraction radiotherapy to $60 \mathrm{~Gy}$ combined with weekly gemcitabine $\left(200 \mathrm{mg} / \mathrm{m}^{2}\right)$. That study was closed due to excessive pulmonary toxicity. 6 of 19 patients developed grade $\geq 3 \mathrm{RP}$, and one patient died of uncontrollable RP. Furthermore, when the total dose of radiotherapy increased to $74 \mathrm{~Gy}$, the incidence of fatal RP was as high as 37\% [25]. These results suggested that induction chemotherapy using gemcitabine was needed careful consideration in term of predictable pulmonary toxicity. In our present study, the rate of grade $\geq 3 \mathrm{RP}$ in patients received gemcitabine induction chemotherapy was 5.3\%. This number was lower than that in the studies listed above. In our study, most patients received concurrent chemoradiotherapy with paclitaxel and carboplatin. Furthermore, the dose of thoracic radiotherapy was $60 \mathrm{~Gy}$ (Standard dose) instead of 74 Gy (High dose), according to the result of RTOG 0617 [29]. Also, the use of IMRT technique for locally advanced NSCLC in our study was associated with lower rates of severe RP [30].

Taxanes, such as paclitaxel and docetaxel, were common chemotherapeutic regimens with high efficacy in NSCLC. Comparison of taxanes based and gemcitabine bases chemotherapy has been performed in several studies. In the clinical trial CALGB 30105, patients with locally advanced NSCLC were randomly assigned to induction chemotherapy with either paclitaxel with carboplatin or gemcitabine with carboplatin followed by thoracic radiotherapy (74-Gy). The rate of grade $\geq 3 \mathrm{RP}$ were 16.2 and $39.1 \%$ in the paclitaxel group and gemcitabine group, respectively. The rate of RP was significantly higher in patients who received gemcitabine induction chemotherapy than that in patients received paclitaxel $(P=0.046)$. In a retrospective study [27], the rate of $R P$ for gemcitabine induction group was higher than that for docetaxel induction group (31.0\% Vs. 20.8\%) but did not reach the significant difference $(P=0.314)$. In our study, compared with docetaxel group, we found a higher incidence of grade $\geq$ $3 \mathrm{RP}$ in the gemcitabine group (25.5\% Vs. $13.2 \%, P=0.005)$. Furthermore, RP occurred earlier in the gemcitabine group than that in the docetaxel group $(P=0.026)$. The results of this study suggested that gemcitabine-based induction chemotherapy, followed by radiotherapy, was associated with a high incidence of RP. Modification of gemcitabine dosage or cycles before radiotherapy or limitation in radiotherapy planning might reduce pulmonary toxicity.

The lung is composed of massive parallel functional subunits. Even if some subunits were damaged by X-rays, the function of others could still operate normally. Therefore, the incidence of RP is related to the volume of the lung exceeding the lung radio-tolerant dosage. Numerous studies demonstrated that dose-volume parameters, such as lung $\mathrm{V}_{5}, \mathrm{~V}_{10}, \mathrm{~V}_{20}, \mathrm{~V}_{30}, \mathrm{~V}_{50}$, and MLD, could efficiently predict the occurrence of RP. In our study, all dosimetric parameters considered in the study (lung $\mathrm{V}_{5}, \mathrm{~V}_{20}, \mathrm{~V}_{30}$, and MLD) correlated significantly with RP in all patients and in the subgroup of patients who received gemcitabine induction chemotherapy. On multivariate analysis, only lung $V_{30}$ was identified as an independent predictor for grade $\geq$ $2 \mathrm{RP}$, findings that correspond with those from several publications [31-33]. The results of Hernando ML et al.' study [34] showed that $V_{30} \geq 18 \%$ was one of the best predictors of severe acute RP among patients treated with definitive external beam radiotherapy. The observed incidence of RP was $24 \%$ for patients with $V_{30} \geq 18$ and $6 \%$ for those with $\mathrm{V}_{30}<18 \%$. The cut-off value of lung $\mathrm{V}_{30}$ in our study was set as $14.2 \%$ according to the calculation the highest Youden

Table 4 The RP occurrence in NSCLC patients treated with gemcitabine-based induction chemotherapy

\begin{tabular}{|c|c|c|c|c|c|c|c|c|}
\hline Authors & Year & $\mathrm{N}$ & IC & Cycles of IC & RT dose (Gy) & CCRT & RP (Grade, \%) & Ref \\
\hline Guilbault C & 2017 & 142 & Gemcitabine+ Cisplatin & 2 & 60 & Gemcitabine+ Cisplatin & $\geq 3,10 \%$ & 10 \\
\hline Kosmidis P & 2007 & 43 & Gemcitabine+Paclitaxel & 2 & 63 & Paclitaxel & $\geq 2,22 \%$ & 21 \\
\hline Schallier D & 2009 & 64 & Gemcitabine+Carboplatin+ Paclitaxel & 3 & 66 & - & $\geq 3,12.5 \%$ & 22 \\
\hline Blanco R & 2008 & 56 & Gemcitabine+Cisplatin & 3 & 68.4 & Gemcitabine & $\geq 3,34 \%$ & 23 \\
\hline Belderbos J & 2007 & 78 & Gemcitabine+Cisplatin & 2 & 66 & - & $\geq 3,14 \%$ & 24 \\
\hline Socinski MA & 2008 & 26 & Gemcitabine+Carboplatin & 2 & 74 & Gemcitabine & $\geq 3,37 \%$ & 25 \\
\hline Arrieta $\mathrm{O}$ & 2009 & 19 & Gemcitabine+Carboplatin & 2 & 60 & Gemcitabine & $\geq 3,31.6 \%$ & 26 \\
\hline Kocak M & 2009 & 39 & Gemcitabine+Cisplatin & 3 & 66 & Docetaxel+cisplatin & NR. $31 \%$ & 27 \\
\hline Driesen $\mathrm{P}$ & 2013 & 49 & Gemcitabine+ Cisplatin & 3 & 63 & Gemcitabine+ Cisplatin & $\geq 3,6.5 \%$ & 28 \\
\hline
\end{tabular}

IC Induction chemotheraoy, RT Radiotherapy, CCRT Concurrent chemoratiotherapy, RP Radiation pneumonitis, NR Not reffered, Ref Reference 
index, findings that were slightly different from other studies. The incidence of RP was as high as $33.6 \%$ for patients with $\mathrm{V}_{30} \geq 14.2$ and $12.9 \%$ for patients with $\mathrm{V}_{30}<14.2 \%$. The cutoff values of lung $\mathrm{V}_{30}$ in patients treated with concurrent chemoradiotherapy [31] or adjuvant radiotherapy after lobectomy [35] were 22 and 13\%, respectively. Furthermore, we created a risk model based on all dosimetric parameters considered in the study. The RP rate was less than $10 \%$ when all dosimetric parameter's constraints were satisfied.

However, there were some limitations in this study. Selective bias still exists because it was a retrospective study. Secondly, radiation-induced pulmonary toxicities included radiation pneumonitis and pulmonary fibrosis. In the present study, only the occurrence and risk factors of RP were analyzed. Furthermore, because most of the patients included in this study were with lung squamous cell carcinoma, there were more male patients and fewer female patients. This limitation made the conclusions less definitive.

\section{Conclusion}

In conclusion, this study found that gemcitabine chemotherapy before thoracic radiotherapy in NSCLC patients was related to a higher incidence of grade $\geq 2 \mathrm{RP}$, compared with docetaxel chemotherapy. Lung $\mathrm{V}_{5}, \mathrm{~V}_{20}, \mathrm{~V}_{30}$, and MLD were all associated with increased risk of grade $\geq 2$ RP in patients received gemcitabine induction chemotherapy followed by radiotherapy. We also created a risk model that could be used in clinical practice. The grade $\geq 2$ RP rate was only $9.4 \%$ for the low-risk group (Lung $\mathrm{V}_{5} \leq 44 \%, \mathrm{~V}_{20} \leq 24 \%, \mathrm{~V}_{30} \leq 14.2 \%$, and $\mathrm{MLD} \leq$ 1226 cGy). These dosimetric parameters are recommended for NSCLC patients who received gemcitabine chemotherapy before thoracic radiotherapy.

\footnotetext{
Abbreviations

ADL: Activities of daily living; AUC: Area under curves; CTCAE: Common Terminology Criteria for Adverse Events; CTV: Clinical tumor volume; DVH: Dose-volume histogram; GTV: Gross tumor volume; IASLC: International Association for the Study of Lung Cancer; MLD: Mean lung dose; NCCN: National Comprehensive Cancer Network; NSCLC: Non-small cell carcinoma; OAR: Organs at risk; PTV: Planning target volume; ROC: Receiver operating characteristic; RP: Radiation pneumonitis
}

\section{Acknowledgements}

We thank all the patients who participated in this study and their families.

\section{Authors' contributions}

LMS: Data collection and analysis and the drafting of the manuscript. XYC: Analysis and interpretation of the data. LC and YC: Conception and study design. XHD: Drafting of the manuscript. All authors read and approved the final manuscript.

\section{Funding}

This study was supported by grants from the Nature Science Foundation of Zhejiang Province (no LY14H160012).

\section{Availability of data and materials}

All data generated or analysed during this study are included in this published article.

\section{Ethics approval and consent to participate}

This study was approved by the Zhejiang Cancer hospital Institutional Review Board.

\section{Consent for publication}

Not applicable.

\section{Competing interests}

The authors declare that they have no competing interests.

\section{Author details}

'Department of radiotherapy, Cancer Hospital of University of Chinese Academy of Sciences, Zhejiang Cancer Hospital, Hangzhou, China. ${ }^{2}$ Institute of Cancer Research and Basic Medical Science of Chinese Academy of Sciences, 1 Banshandong Road, Hangzhou 310022, Zhejiang, China. ${ }^{3}$ The Second Clinical Medical College, Zhejiang Chinese Medical University, Hangzhou, China.

Received: 5 November 2019 Accepted: 9 December 2019

Published online: 16 December 2019

\section{References}

1. Steuer CE, Behera M, Ernani V, Higgins KA, Saba NF, Shin DM, et al. Comparison of concurrent use of thoracic radiation with either carboplatinpaclitaxel or cisplatin-etoposide for patients with stage III non-small-cell lung cancer: a systematic review. JAMA Oncol. 2017;3:1120-9.

2. Curran WJ Jr, Paulus R, Langer CJ, Komaki R, Lee JS, Hauser S, et al. Sequential vs. concurrent chemoradiation for stage III non-small cell lung cancer: randomized phase III trial RTOG 9410. J Natl Cancer Inst. 2011;103:1452-60.

3. Auperin A, Le Pechoux C, Rolland E, Curran WJ, Furuse K, Fournel P, et al. Meta-analysis of concomitant versus sequential radiochemotherapy in locally advanced non-small-cell lung cancer. J Clin Oncol. 2010;28:2181-90.

4. Vokes EE, Herndon JE 2nd, Kelley MJ, Cicchetti MG, Ramnath N, Neill H, et al. Induction chemotherapy followed by chemoradiotherapy compared with chemoradiotherapy alone for regionally advanced unresectable stage III non-small-cell lung cancer: Cancer and leukemia group B. J Clin Oncol. 2007:25:1698-704.

5. Ahmed I, Ferro A, Baby R, Malhotra J, Cohler A, Langenfeld J, et al. Modern induction chemotherapy before chemoradiation for bulky locally-advanced nonsmall cell lung cancer improves survival. J Cancer Res Ther. 2016;12:952-8.

6. Paz-Ares L, de Marinis F, Dediu M, Thomas M, Pujol JL, Bidoli P, et al. Maintenance therapy with pemetrexed plus best supportive care versus placebo plus best supportive care after induction therapy with pemetrexed plus cisplatin for advanced non-squamous non-small-cell lung cancer (PARAMOUNT): a double-blind, phase 3, randomised controlled trial. Lancet Oncol. 2012;13:247-55.

7. Chen $Y$, Huang $Y$, Chen DM, Wu C, Leng QP, Wang WY, et al. RRM1 expression and the clinicopathological characteristics of patients with non-small cell lung cancer treated with gemcitabine. OncoTargets Ther. 2018;11:5579-89.

8. Kouroussis C, Mavroudis D, Kakolyris S, Voloudaki A, Kalbakis K, Souglakos J, et al. High incidence of pulmonary toxicity of weekly docetaxel and gemcitabine in patients with non-small cell lung cancer: results of a dosefinding study. Lung Cancer. 2004;44:363-8.

9. Rabinowits G, Herchenhorn D, Rabinowits M, Weatge D, Torres W. Fatal pulmonary toxicity in a patient treated with gefitinib for non-small cell lung cancer after previous hemolytic-uremic syndrome due to gemcitabine. AntiCancer Drugs. 2003;14:665-8.

10. Guilbault C, Garant A, Faria S, Owen S, Ofiara L, Duclos M, et al. Long-term outcomes of induction carboplatin and gemcitabine followed by concurrent radiotherapy with low-dose paclitaxel and gemcitabine for stage III non-small-cell lung cancer. Clin Lung Cancer. 2017;18:565-71.

11. Butof R, Kirchner K, Appold S, Lock S, Rolle A, Hoffken G, et al. Potential clinical predictors of outcome after postoperative radiotherapy of non-small cell lung cancer. Strahlenther Onkol. 2014;190:263-9.

12. Luna JM, Chao HH, Diffenderfer ES, Valdes G, Chinniah C, Ma G, et al. Predicting radiation pneumonitis in locally advanced stage II-III non-small cell lung cancer using machine learning. Radiother Oncol. 2019;133:106-12.

13. Wen J, Liu H, Wang L, Wang X, Gu N, Liu Z, et al. Potentially functional variants of ATG16L2 predict radiation pneumonitis and outcomes in patients with non-small cell lung cancer after definitive radiotherapy. J Thorac Oncol. 2018;13:660-75. 
14. Palma DA, Senan S, Tsujino K, Barriger RB, Rengan R, Moreno M, et al. Predicting radiation pneumonitis after chemoradiation therapy for lung cancer: an international individual patient data meta-analysis. Int J Radiat Oncol Biol Phys. 2013:85:444-50.

15. Madani I, De Ruyck K, Goeminne H, De Neve W, Thierens H, Van Meerbeeck J. Predicting risk of radiation-induced lung injury. J Thorac Oncol. 2007;2:864-74.

16. Roach M 3rd, Gandara DR, Yuo HS, Swift PS, Kroll S, Shrieve DC, et al. Radiation pneumonitis following combined modality therapy for lung cancer: analysis of prognostic factors. J Clin Oncol. 1995;13:2606-12.

17. Dieleman EMT, Uitterhoeve ALJ, van Hoek MW, van Os RM, Wiersma J, Koolen MGJ, et al. Concurrent daily cisplatin and high-dose radiation therapy in patients with stage III non-small cell lung cancer. Int J Radiat Oncol Biol Phys. 2018;102:543-51.

18. Senan S, Brade A, Wang LH, Vansteenkiste J, Dakhil S, Biesma B, et al. PROCLAIM: randomized phase III trial of pemetrexed-cisplatin or etoposidecisplatin plus thoracic radiation therapy followed by consolidation chemotherapy in locally advanced nonsquamous non-small-cell lung cancer. J Clin Oncol. 2016;34:953-62.

19. Scagliotti GV, Parikh P, von Pawel J, Biesma B, Vansteenkiste J, Manegold C, et al. Phase III study comparing cisplatin plus gemcitabine with cisplatin plus pemetrexed in chemotherapy-naive patients with advanced-stage nonsmall-cell lung cancer. J Clin Oncol. 2008;26:3543-51.

20. Sahin $I H$, Geyer Al, Kelly DW, O'Reilly EM. Gemcitabine-related pneumonitis in pancreas adenocarcinoma--an infrequent event: elucidation of risk factors and management implications. Clin Colorectal Cancer. 2016;15:24-31.

21. Kosmidis P, Fountzilas G, Baka S, Samantas E, Dimopoulos AM, Gogas H, et al. Combination chemotherapy with paclitaxel and gemcitabine followed by concurrent chemoradiotherapy in non-operable localized non-small cell lung cancer. A hellenic cooperative oncology group (HeCOG) phase II study. Anticancer Res. 2007;27:4391-5.

22. Schallier D, Bral S, Ilsen B, Neyns B, Fontaine C, Decoster L, et al. Final overall results of a study with a novel triplet induction chemotherapy regimen (PACCAGE) followed by consolidation radiotherapy in locally advanced inoperable non-small cell lung cancer (NSCLC). J Thorac Oncol. 2009;4:728-35.

23. Blanco R, Sole J, Montesinos J, Mesia C, Algara M, Terrassa J, et al. Induction chemotherapy with cisplatin and gemcitabine followed by concurrent chemoradiation with twice-weekly gemcitabine in unresectable stage III non-small cell lung cancer: final results of a phase II study. Lung Cancer. 2008;62:62-71.

24. Belderbos J, Uitterhoeve L, van Zandwijk N, Belderbos $H$, Rodrigus P, van de Vaart $P$, et al. Randomised trial of sequential versus concurrent chemoradiotherapy in patients with inoperable non-small cell lung cancer (EORTC 08972-22973). Eur J Cancer. 2007;43:114-21.

25. Socinski MA, Blackstock AW, Bogart JA, Wang X, Munley M, Rosenman J, et al. Randomized phase II trial of induction chemotherapy followed by concurrent chemotherapy and dose-escalated thoracic conformal radiotherapy (74 Gy) in stage III non-small-cell lung cancer: CALGB 30105. J Clin Oncol. 2008;26:2457-63.

26. Arrieta O, Gallardo-Rincon D, Villarreal-Garza C, Michel RM, Astorga-Ramos AM, Martinez-Barrera $L$, et al. High frequency of radiation pneumonitis in patients with locally advanced non-small cell lung cancer treated with concurrent radiotherapy and gemcitabine after induction with gemcitabine and carboplatin. J Thorac Oncol. 2009;4:845-52.

27. Kocak M, Ozkan A, Mayadagli A, Parlak C, Bilici A, Seker M, et al. Induction chemotherapy and chemoradiation therapy for inoperable locally advanced non-small-cell lung cancer: a single-institution review of two different regimens. Clin Lung Cancer. 2009;10:124-9.

28. Driesen P, Lambrechts M, Kraaij K, Soldatenkova V, Chouaki N, Colinet B. A phase II single-arm study of induction chemotherapy with cisplatin and gemcitabine followed by concurrent cisplatin and gemcitabine with thoracic radiation for unresectable locally advanced non-small cell lung cancer. Therapeut Adv Med Oncol. 2013;5:159-68.

29. Bradley JD, Paulus R, Komaki R, Masters G, Blumenschein G, Schild S, et al. Standard-dose versus high-dose conformal radiotherapy with concurrent and consolidation carboplatin plus paclitaxel with or without cetuximab for patients with stage IIIA or IIIB non-small-cell lung cancer (RTOG 0617): a randomised, two-by-two factorial phase 3 study. Lancet Oncol. 2015;16:187-99.

30. Chun SG, Hu C, Choy H, Komaki RU, Timmerman RD, Schild SE, et al. Impact of intensity-modulated radiation therapy technique for locally advanced non-small-cell lung cancer: a secondary analysis of the NRG oncology RTOG 0617 randomized clinical trial. J Clin Oncol. 2017;35:56-62.
31. Kobayashi H, Uno T, Isobe K, Ueno N, Watanabe M, Harada R, et al. Radiation pneumonitis following twice-daily radiotherapy with concurrent carboplatin and paclitaxel in patients with stage III non-small-cell lung cancer. Jpn J Clin Oncol. 2010;40:464-9.

32. Zhao $Y$, Chen $L$, Zhang S, Wu Q, Jiang $X$, Zhu H, et al. Predictive factors for acute radiation pneumonitis in postoperative intensity modulated radiation therapy and volumetric modulated arc therapy of esophageal cancer. Thorac Cancer. 2015;6:49-57.

33. Jin X, Lin B, Chen D, Li L, Han C, Zhou Y, et al. Safety and outcomes of volumetric modulated arc therapy in the treatment of patients with inoperable lung cancer. J Cancer. 2019;10:2868-73.

34. Hernando ML, Marks LB, Bentel GC, Zhou SM, Hollis D, Das SK, et al. Radiation-induced pulmonary toxicity: a dose-volume histogram analysis in 201 patients with lung cancer. Int J Radiat Oncol Biol Phys. 2001:51:650-9.

35. Claude L, Perol D, Ginestet C, Falchero L, Arpin D, Vincent M, et al. A prospective study on radiation pneumonitis following conformal radiation therapy in non-small-cell lung cancer: clinical and dosimetric factors analysis. Radiother Oncol. 2004;71:175-81.

\section{Publisher's Note}

Springer Nature remains neutral with regard to jurisdictional claims in published maps and institutional affiliations.
Ready to submit your research? Choose BMC and benefit from:

- fast, convenient online submission

- thorough peer review by experienced researchers in your field

- rapid publication on acceptance

- support for research data, including large and complex data types

- gold Open Access which fosters wider collaboration and increased citations

- maximum visibility for your research: over $100 \mathrm{M}$ website views per year

At BMC, research is always in progress.

Learn more biomedcentral.com/submissions 